\title{
PANDEMIA DA COVID-19 E A HISTÓRIA DA EDUCAÇÃO DA POPULAÇÃO NEGRA ${ }^{1}$
}

\section{Pandemia COVID-19 y la historia de la educación de la población negra}

Covid-19 Pandemic and the History of the Education of the Afrodescendant population

\author{
CAIRO MOHAMAD IBRAHIM KATRIB \\ Universidade Federal de Uberlândia (Brasil) \\ cairomohamad@gmail.com \\ LUCIANE RIBEIRO DIAS GONÇALVES \\ Universidade Federal de Uberlândia (Brasil) \\ luciane21dias@gmail.com
}

\section{RESUMO}

A pandemia da Covid-19 retoma as discussões sobre processos históricos excludentes produzidos pelo racismo e acelerado, na atualidade, pela doença. A proposta deste texto é contextualizar a história da Educação do povo negro brasileiro e o papeldas ações compensatórias possibilitadas pelas políticas públicas nacionais como tentativa de reparação dos séculos de silenciamento da população negra e de sua contribuição na construçãoe na efetivação da nossa cultura e da nossa sociedade. Envidenciamos aqui, as visões distorcidas dessa contribuição, posto que entendemos que elas ao se projetarem no cenário nacional,permitem questionamentos significativos, dentre eles a importância

1 Esse artigo é uma versão atualizada do material publicado em: Borges, M. C, Richter, L. M., \& Vieira, V. M. O. (2017). A formação de professores/as: um olhar multidimensional. São Carlos: Pedro \& JoãoEditores. 
que africanos e afrodescendentes tiveram e têm para a concretização de nossa identidade cultural. Processos educacionais devem ser revistos para superarem o eurocêntrismo e um legado histórico da escravização e dasegregação que sustenta uma sociedade racialmente injusta e influencia a pedagogia. A póspandemia deverá levar em consideração essas reflexões para que possa contribuir para contrução de uma sociedade mais equinanime.

Palavras chave: Pandemia; História da Educação; População negra; Racismo; Equidade.

\section{RESUMEN}

La pandemia Covid-19 retoma las discusiones sobre los procesos históricos excluyentes producidos por el racismo y acelerados, hoy, por la enfermedad. El propósito de este texto es contextualizar la historia de la educación del pueblo negro brasileño y el papel de las acciones compensatorias posibilitadas por las políticas públicas nacionales como un intento de reparar siglos de silencio para la población negra y su contribución a la construcción y efectividad nuestra cultura y cultura nuestra sociedad. Aquí destacamos las visiones distorsionadas de este aporte, ya que entendemos que cuando se proyectan en el escenario nacional, permiten interrogantes significativos, entre ellos la importancia que tuvieron y tienen los africanos y afrodescendientes para la realización de nuestra identidad cultural. Los procesos educativos deben revisarse para superar el eurocentricidad y un legado histórico de esclavitud y segregación que sostiene una sociedad racialmente injusta e influye en la pedagogía. La pospandemia debe tener en cuenta estas reflexiones para que pueda contribuir a la construcción de una sociedad más equitativa.

Palabras clave: Pandemia; Historia de la educación; Población negra; Racismo; igualdad.

198 | INTEREDU № 4 VOL. I (JuLIO 2021) PÁGs. 197-227. ISSN: 2735-6523 


\begin{abstract}
The Covid-19 pandemic resumes discussions about exclusionary historical processes produced by racism which has been accelerated, today, by this disease. The purpose of this text is to contextualize the history of education of the AfroBrazilian people and the role of compensatory actions made possible by national public policies as an attempt to repair centuries of silence for the Afro-descendant population and their contribution to the construction and effectiveness of our culture and society. Here, we highlight the distorted views of this contribution, since we understand that when they are projected on the national scene, they allow the elaboration of significant enquiries, one of them is the importance that Africans and Afro-descendants have had in the construction of our cultural identity. Educational processes must be revised to overcome Eurocentricity and a historical legacy of enslavement and segregation that sustains a racially unjust society which also influences education. The post-pandemic society should take these reflections into account so that it can contribute to the construction of a more equalitarian society.
\end{abstract}

Key words: Pandemic; History of education; Afro-descendant population; Racism; equity.

\title{
1. INTRODUÇÃO
}

O contexto pandêmico vivenciado mundialmente, desde o ano de 2020, exacerbou o processo histórico de exclusão da população negra brasileira. A dificuldade, ou até mesmo políticas públicas de exclusão, fizeram com que essa população estivesse antigamente e reverberando nos tempos atuais com os piores índices relativos a acesso aos bens públicos e, emparticular a sua presença no sistema educacional: 
A pandemia da COVID-19 no Brasil demonstra que regiões e populações sãocolocadas em condições de maior vulnerabilidade aos riscos de contaminaçãoe morte. Partimos desses pressupostos para analisar o cenário nacional da pandemia da COVID-19. O país ocupa a 79a posição no ranking de desenvolvimento humano da Organização das Nações Unidas 25. Nos últimosanos, vê-se um aumento dos indicadores de desigualdade, atingindo sobretudoa população negra. Em 2018, no Município do Rio de Janeiro, 30,5\% das pessoas negras (pretas e pardas) residiam em favelas, contra $14,3 \%$ de pessoasbrancas 26 . Em termos de cobertura de saneamento básico, negros são a maioria vivendo em locais com infraestrutura inadequada e exposição a vetores de doença: $12,5 \%$ de negros residem em locais sem coleta de lixo e apenas $6 \%$ da população branca; sem abastecimento de água por rede geral, os negros representam $17,9 \%$, e brancos $11,5 \%$; sem esgotamento sanitário por rede coletora ou pluvial, negros representam $42,8 \%$ da população contra 26,5\% debrancos (Oliveira et al., 2020, p. 5).

Certamente, a pandemia do Covid 19, diferentemente do que foi socializado, com a atribuição de um fator democrático do vírus que acometeria a população de forma igualitária, entendemos que para a população negra a doença tem sido mais avassaladora. As assimetrias históricas que marcam a população negra tornaram-se mais perceptíveis no momento pandêmico.Desta forma, as marcas do vírus foram muito mais aniquiladoras para a população negra.

Mais do que nunca a Educação antirracista faz-se necessária. Precisamos articular as questões pedagógicas e curriculares ao enfrentamento das diferenças que hierarquizam e subalternizam desde a discriminação 
racial/gênero/classe até processos de invisibilização que provocam a evasão e o fracasso escolar de uma grande parte da população.

A situação pós-pandêmica exige como tarefa política a insurgência da população negra na escola. A relevância disso é apresentada nesse artigo na forma de contextualização histórica. $O$ princípio das africanidades que advoga a importância de revisitarmos o passado para que possamos construir um futuro que seja transformador é o balizador deste artigo.

A pretensão deste texto é de contextualizar a história da Educação do povo negro brasileiro. A história do negro no Brasil tem sido bastante evidenciada nas últimas décadas. Em detrimento disso, uma série de ações compensatórias possibilitadas pelas políticas públicas nacionais se concretizaram numa tentativa de reparação dos séculos de silenciamento da população negra e de sua contribuição na construção e na efetivação da nossa cultura e da nossa sociedade. Entretanto, visões distorcidas dessa contribuição ainda se projetam no cenário nacional, questionando a importância que africanos e afrodescendentes tiveram e têm para a concretização de nossa identidade cultural.

O isolamento tendencioso da contribuição positiva dessas populações na nossa trajetória histórica pode ser presenciado, por mais que se tenha revertido esse quadro de silenciamento, nos bancos escolares do país.

É evidente que nem mesmo o cumprimento da Lei $n^{\circ} 10.639$ (2003), que referenda o ensino da cultura e da história dos africanos e afrodescendentes nos diferentes níveis da educação nacional,obtém êxito continuado no que se refere à visibilidade da importância e do significado dos conhecimentos dos negros escravizados no desenvolvimento do país.

Historicamente, esse jogo de interesse em dificultar a ascensão histórica e cultural do negro no Brasil teve a escola como sua grande aliada. Isso pode ser constatado se levarmos em consideração as políticas 
de acesso à educação no país ao longo de sua história. Exemplo disso éa legislação criada para dificultar o ingresso do negro ao sistema escolar. A partir dos anos de 1850, o direito à educação do negro passa a ser balizado por decretos ${ }^{2}$ que definiam o acesso e o formato da educação a ser recebida, levando em consideração a sua condição social.

É perceptível que o acesso da população negra à educação é historicamente efetivado nas contradições sociais e por interesses políticos e ideológicos, uma vez que em uma sociedade na qual predominou, por vários séculos, a ideia de um Brasil homogêneo, desprezando a sua diversidade cultural, a educação foi destinada, em grande parte, à população branca e de condiçõessociais mais elevadas.

Diante desse contexto, os negros viveram a mercê desses estigmas sociais que criaram imagens distorcidas de sua identidade cultural e dos conhecimentos herdados, fruto das invenções e reinvenções que objetivavam a tentativa de consolidação de um sentido identitário eurocêntricopara o país.

Nos anos de 1920, aparecem as primeiras tentativas de reversão desse quadro com os questionamentos sobre a formação cultural do povo brasileiro. Contudo, é a partir dos anos de 1990 que essa visão começa, de fato, a ser questionada, revisitada e modificada, de forma a descontruir a visão de Brasil homogêneo e efetivar a de um país plural, multifacetado e diverso.

Atualmente, a ideia de país plural toma a cena das principais transformações sociais, políticas, econômicas e educacionais. A

\footnotetext{
${ }^{2}$ O Decreto $n^{0}$ 1.331, de 17 de fevereiro de 1854, estabelecia que nas escolas brasileiras não seriam admitidos escravizados e a previsão para acesso de adultos negros dependia da disponibilidade de professores para ensiná-los. Já o Decreto no 7031-A, de 6 de setembro de 1878 , estabelecia que os negros só poderiam estudar no período noturno.
}

202 | INTEREDU № 4 VOL. I (JULIO 2021) PÁGS. 197-227. ISSN: 2735-6523 
diversidade passou a ser reconhecida e valorizada como processo significativo de desencadeamento de novos olhares sobre a educação nacional. A escola passa a ser vista como um espaço privilegiado para o estudo da pluralidade, valorizando os saberes, os fazeres e as práticas dos diversos grupos sociais representados nesse espaço, como frisa Gontijo (2003).

Nessa perspectiva, o ideário da diversidade passa a compor os pressupostos fundamentais da Constituição Federal no que concerne a valorização e o respeito à diversidade cultural, como destaca Silvério (2005). Isso, entretanto, não garante que o respeito às diferenças seja consolidado. $\mathrm{O}$ que presenciamos é um país que caminha para a confirmação do respeito às diferenças, racial e/ou de gênero, promovendo a justiça social, a valorização e o respeito da multiplicidade cultural,além da manutenção de valores supremos de uma sociedade fraterna, pluralista e sem preconceitos.

Em uma sociedade formada por diferentes etnias, muitas vezes as relações estabelecidas socialmente e culturalmente são permeadas por conflitos, mas é necessário compreender que para se viver democraticamente em um país plural é preciso respeitar os diferentes que a constituem (Brasil, 1998).

Embora o processo de escravização tenha sido extinto legalmente a mais de um século, ocorrem, diariamente, atitudes que configuram preconceito e racismo em diversos espaços sociaise também nas escolas. Para enfrentar e resolver questões decorrentes de séculos de silenciamento e subjugação, diversos setores da sociedade civil em articulação com os movimentos sociais têmlutado para a mudança desse cenário, para que haja equidade no exercício dos direitos de igualdade e justiça defendidos pela Constituição Federal, tida como uma legislação antidiscriminatória, por estabelecer a discriminação racial como crime. 
É válido destacarmos, como aponta Oliveira (2004), que no Brasil é muito difícil valorizar e assumir como parte da identidade nacional a identidade racial negra, já que ser afrodescendente em um país como o nosso é um processo extremamente difícil e doloroso, considerando que os modelos "bons", "positivos" e de "sucesso" de identidades negras não são muitos e o respeito à diferença inexiste em meio à diversidade de identidades raciais/étnicas.

Muitos fatores, dentre eles a luta de movimentos sociais, contribuíram para a elaboraçãode políticas públicas nas várias esferas governamentais voltadas para os diversos setores da sociedade. Dessa forma, políticas de reparações, de reconhecimento e de valorização de ações afirmativas foram elaboradas e consideradas de responsabilidade do Estado, este deve promovê-las e incentivá-las.

Tratando especificamente da educação, uma série de políticas públicas foram implementadas na tentativa de aproximar a educação escolar da realidade sociocultural dos (das) estudantes. Uma delas é a Lei no 10.639 (2003), que instituiu, no currículo do ensino fundamental e médio, a obrigatoriedade do ensino de história da África e dos africanos, como forma de resgatara contribuição dos negros na formação do povo e da cultura brasileiros.

A referida lei é fruto de um amplo processo de luta do Movimento Negro Brasileiro. Sua concepção originou-se das discussões ocorridas durante as várias conferências mundiais sobre a temática, em especial a III Conferência Mundial Sobre o Racismo, a Discriminação Racial, a Xenofobia e Formas Correlatas de Intolerância, ocorrida em Durban, na África do Sul, no ano de2001, em que 170 nações chamaram a atenção mundial para o compromisso político no combate ao racismo e à 
discriminação nos mais diversos países, em especial, naqueles em processo de desenvolvimento.

O Movimento Negro Brasileiro já vinha denunciando, há várias décadas, o quadro discriminatório vivenciado em nosso país, bem como a falta de comprometimento dos governantes sobre a questão. Tais pressões fizeram com que o governo brasileiro atentasse para o contexto da desigualdade racial e sancionasse a Lei no 10.639 (2003) como possibilidade de fazer valeras alterações trazidas pela Lei de Diretrizes e Bases da Educação Nacional (LDBEN) - Lei no 9.394 (1996), que estabelece a necessidade de abordagem da diversidade e pluralidade cultural, também referendada pelas diretrizes contidas nos Parâmetros Curriculares Nacionais (Brasil, 2007).

A referida lei atribui a necessidade de uma atenção maior aos currículos no tocante à obrigatoriedade do estudo da história da África, dos africanos e dos negros no Brasil, enfatizandosuas contribuições para a constituição da sociedade brasileira em seus segmentos políticos, econômicos, culturais e sociais, na tentativa de promover uma visibilidade positiva ao papel exercido por esses atores sociais na formação de nossa sociedade.

Nos últimos anos, o cumprimento da Lei no 10.639 (2003), em especial a sua eficácia, tem sido questionada, na maioria dos casos em virtude da pouca cobrança das instâncias governamentais de sua aplicabilidade ou por conta da dualidade interpretativa em relação à forma e ao contexto de sua efetivação nos variados espaços escolares. Entretanto, aqueles que acreditam na consolidação dessa Lei estão cientes de que ela, por si só, não reverterá o olhar discriminatório que é lançado, ainda, sobre a população negra, até mesmo pelo fato das diversas interpretações que ela assume no olhar dos governantes, gestores e educadores.

Nesse caminho, múltiplas interpretações e processos se concretizaram e se consolidaram,tendo como foco a institucionalização 
das políticas de reparação das distorções étnicas e raciais no Brasil. Deparamo-nos, cotidianamente, no espaço escolar com situações geradoras do silenciamento e da invisibilidade do negro. Dessa forma, a partir daqui, refletiremos, sobre algumas evidências do conflito racial brasileiro, acreditando que essa reflexão possa contribuir para o enfrentamento do racismo e as possibilidades de intervenção nesse processo, principalmente pela ação docente. Para tanto, buscaremos compreender quem é esse negro que seencontra na escola, como ele é visto e tratado nesse espaço que é (ou deveria ser), por excelência, lócus do saber, da valorização do outro e do respeito às diferenças.

\section{OUTRO/NEGRO NO CONTEXTO ESCOLAR}

Antropologicamente, o outro se refere a uma construção identitária. Na sociedade moderna, o outro é visto como o diferente, o estrangeiro, o estranho, havendo a negação a esse outro. Ele não pode existir porque não legítimo. A existência e afirmação do outro coloca em risco a existência e a afirmação daquilo que "sou". O outro é o estranho, o que não é, posto que quem é sempre sou "eu".

Para este artigo é importante pensar como se dá o encontro com o outro/negro. A análiseque segue se refere à dimensão do "encontro com o outro", de acordo com alguns autores.

Em um artigo no qual apresentam o conceito de estrangeirice (diferenças radicais em termos de aspectos sociais, culturais eidentitários), Souza e Gallo (2002) discutem a aproximaçãocom o outro, afirmando a exclusão - ou a morte - deste na dimensão político-social e também afetiva. Na dimensão afetiva, os autores recorrem aos pressupostos de Freud e outros autores da psicanálise sobre a perturbação que a presença 206 | INTEREDU № 4 VOL. I (JULIO 2021) PÁGS. 197-227. ISSN: 2735-6523 
do estranho/estrangeiro gera entre/em nós. No aspecto político-social, que nos interessa sobremaneira, eles se valem dos escritos de Foucault que correlacionam o racismo ao poder e explicitam os elementos que articulam o racismo de Estado.

De acordo com os autores, "'na analítica foucaultiana', o racismo é o mecanismo pelo qual o Estado justifica seu direito de matar, numa sociedade biopolítica, fundada [e justificada] na afirmação da vida", uma vez que "a eliminação do diferente, do menos dotado, do menos capaz implica a purificação da raça, o melhoramento da população como um todo" (Souza \& Gallo, 2002, p. 47). Na conclusão da análise, os autores pontuam que,

Se o biopoder permite a emergência do racismo de Estado, que leva a exclusão do diferente ao limite de sua eliminação pela morte, também é certo que a biopolítica permite a criação de novas ferramentas e instrumentos de luta, de novas armas que podem agenciar a eclosão das diferenças. Tudo depende de como se faz uso dos poderes e dos contrapoderes. (Souza \& Gallo, 2002, p.59).

De certa maneira, as discussões que serão aqui tecidas falam de como se faz uso dos poderes e dos contrapoderes, considerados pelos autores como biopoder e a biopolítica, respectivamente. Isso, na medida em que, conhecendo os pensamentos sobre a diferença e o outro, é possível pensar em formas de subjugar ou de libertar as pessoas que enfrentam tal impasse.

Segundo Jodelet (1999), o encontro com o outro se faz através de "processos mentais pelos quais se operam a descrição e o julgamento das pessoas ou de grupos" (p. 59), caracterizados por "pertencerem a uma categoria social ou pelo fato de apresentar um ou mais tributos próprios a esta categoria". 
Jodelet (1999) complementa, conceituando o estereótipo como "um processo de simplificação próprio ao pensamento do senso comum" (p. 60), e esclarece sobre a teoria dacategorização social, em que "haveria uma tendência para selecionar e interpretar as informaçõesde que dispomos sobre os indivíduos e grupos de maneira congruente com o que nós pensamos da categoria na qual nós as colocamos" (p. 60). Ainda analisando as diferenças, a autora ressalta que as mesmas podem ocasionar "consequências dramáticas no plano das percepções e dos comportamentos, dando lugar a discriminações, na medida em que são acompanhadas de viesesfavoráveis ao grupo do qual somos membros, com uma tolerância a desfavorecer os grupos dos quais nos distinguimos" (pp. 60-61).

A contribuição da autora para as análises do encontro com o outro se apresenta na argumentação de que as pessoas têm maior facilidade de se aproximar e favorecer o grupo a que atribui a sua própria pertença, consequentemente as representações sociais positivas preponderantemente são ligadas ao grupo de pertença.

Para Munanga (1999), as relações raciais no Brasil e na América Latina se diferenciaram pelo processo de mestiçagem que imputou à sociedade um elemento transitório na identidade nacional: o mestiço. Segundo o autor, esse processo

teria sido prejudicado pela ideologia e pelo ideal de branqueamento. Se todos aspiram à brancura para fugir das barreiras raciais que impedem sua ascensão socioeconômica e política, como entender que possam construir uma identidade mestiça quando o ideal de todos é branquear cada vez mais para passar à categoria branca? (Munanga, 1999, p. 108). 
Desta forma, a discussão acerca das relações raciais no Brasil não pode prescindir do processo e da ideologia do branqueamento. Como ilustra Skidmore (1989 como citado em Munanga, 1999, p. 110), o “branqueamento ofereceria o melhor caminho para aplacar essa ameaça de conflitos: antes que o problema negro venha surgir no Brasil... seria resolvido pelo amor".

A ameaça dos conflitos raciais e a necessidade de construção de uma identidade nacional, sentidas pela população brasileira, encontrou consonância no processo de mestiçagem, visto como eficiente porque capaz de manter uma estrutura racista sem hostilidades abertas, conforme argumenta Munanga (1999). Decorre daí, o esforço dos movimentos negros

em redefinir o negro, dando-lhe consciência política e uma identidade étnica mobilizadoras, contrariando a ideologia de democracia racial [...]. O mestiço brasileiro simboliza a ambiguidade: ele é "um e outro", "o mesmo e o diferente", "nem um nem outro", "ser e não ser", "pertencer e não pertencer". (Munanga, 1999, pp. 125-126).

Por mais problemática que possa parecer a relação com o outro, não existe outra forma de entender o mundo que não seja estabelecido pelas relações e encontros entre outros. A questãocentral deste debate encontrase nos resultados desses encontros com o outro. Geralmente esse encontro tem se configurado como formas de classificar e hierarquizar o outro pela diferença queele tenha. Os movimentos de resistência são, nesse caso, uma negação da padronização das formasde desigualdade e discriminação que as relações possam ocasionar. Conforme sintetiza Candau (2002), "as pessoas e os grupos sociais têm o direito a ser iguais quando a diferença 
os inferioriza, e o direito a ser diferentes quando a igualdade os descaracteriza" (p. 128).

É necessário discutir a relação espaço-tempo, a exclusão, o preconceito, a discriminaçãoe o conflito racial na escola, pois a ideologia do branqueamento ainda é latente nas relações sociaise imputa o outro como algo externo a essas relações, o "estrangeiro", a que muitas vezes se justifica até o ato de "matar" para evitar sua incômoda presença.

Nas relações cotidianas e no senso comum, são estabelecidos o julgamento e a "categorização", em que fica explícita a preferência por organizar a sociedade de forma congruente, excluindo o diferente, por isso a presença do outro/negro no contexto escolar tem provocado a pedagogia. Conforme enfatizado até aqui, as relações raciais no Brasil são conflituosas e é premente que a escola se proponha a usar o "contrapoder" para transformar a sociedade.

A emergência de uma sociedade globalizada traz consigo algumas discussões que são pertinentes a todos os campos das ciências e, em particular, à educação. $\mathrm{O}$ distanciamento entre a identidade (subjetividade, individualidade e alteridade) e a diferença e a coletividade se mostramnos campos teóricos e práticos, constantemente. É no bojo dessas discussões que emerge este trabalho, cujo pano de fundo está justamente no confronto entre o eu e o outro no contexto escolare o que ambos constroem como representações sociais das pessoas envolvidas.

Desse modo, convém indagar porque essas constatações podem ser importantes para o debate sobre a educação das relações étnico-raciais. De fato, esse campo de debate traz à tona a questão acerca do tipo de indivíduo que queremos formar e para qual tipo de sociedade. As falas iniciais de professores(as) em processo de formação sobre educação das 
relações étnico-raciais destacam a importância de "reconhecer e valorizar a raça negra" como possibilidade de que isso possa mudar a "autoestima" e transformar a sociedade.

Sobre esse aspecto, analisando as dimensões e sobrevivências de pensamentos emeducação em territórios africanos e afro-brasileiros, Silva (2000) busca entender como se configura para o negro a importância do processo de construção das pessoas, situando aí as contribuições da educação escolar. A autora revela que esse processo tem papel importante nas relações sociais e que essa relevância é continuada na escola.

Na concepção de pessoa educada nas africanidades, Silva (2000) mostra que, antes de ir para a escola, há um processo formativo feito pelas inter-relações familiares e comunidade. Neste processo, “o idoso é respeitado por deter vários conhecimentos e como a pessoa responsável portransmitir conhecimentos, por isso o respeito aos mais velhos é um valor supremo". Neste sentido,a visão de pessoa educada é aquela "capaz de ao longo da vida ir tornando-se sábia" e empenhar-se em fortalecer a comunidade (Silva, 2000, p. 70). Nesse contexto, a autora apresenta a educação como um valor de refúgio, pois é

um valor da cultura africana que sobrevive sob a opressão da escravidão e da colonização e que foram suporte para os novos significados com que os escravizados e seus descendentes têm forjado a vida, os intercâmbios entre pessoas e grupos de diferentes classes sociais, raízes culturais. (Silva, 2000, p. 70).

Portanto, pensar a educação como valor de refúgio demonstra o significado e a relevância deste processo na formação identitária e da autoestima.

Já o processo de formação docente e a pedagogia se apresentam como campos que merecem atenção, pois poderão definir o perfil do 
profissional que estará cotidianamente tratandodas relações raciais na escola. A forma como tais profissionais encaram a educação étnico-racial, o preconceito e o racismo é prioritária ao modelo de sociedade a que se pretende chegar.

Disso resultam questionamentos como: será que a educação tem sido um valor de refúgiopara a população brasileira? O professor(a) teria suporte teórico em sua formação para tornar sua prática pedagógica transformadora?.

Pinto (2000), em uma pesquisa no curso de magistério, verificou se essa formação daria condições ao professor de lidar com a diversidade étnico-racial. Tal estudo, além de evidenciar que esse tema é abordado em momentos específicos da formação, pois a maioria o achaproblemático e delicado, demonstra que o curso não tem fornecido elementos suficientes para lidar com a temática, por isso a pesquisadora atenta para a tarefa da formação docente em uma perspectiva reflexiva.

A pesquisadora considera a possibilidade de que "todas as disciplinas possuem aspectos em seus conteúdos que permitem prestar atenção às questões de justiça social e diversidade" (Pinto, 2000, p. 131). Apoiada no que Canen (1997) denomina plano das interações sociais, ela declara que existe a necessidade de levar em consideração, além dos conteúdos, os gestos e asatitudes. Desse modo, a formação do educador a respeito da temática deve ser suficiente para que ele "tenha condições de pressionar a escola em que irá atuar para que esta também se imbua da importância do tema" (Pinto, 2000, p. 132).

A partir da análise de histórias de vida de negros, Souza (2000), em seu estudo sobre as relações interétnicas na escola, demonstra como preconceito e discriminação contribuem para a autoestima negativa e 
como a escola tem papel importante na afirmação do racismo. Pondera a autora que é na escola que a criança tem um verdadeiro choque com a percepção do significado de ser negro nessa sociedade e que "os mecanismos discriminatórios afetam o aluno negro presente no sistema educacional em termos organizacionais, curriculares e na socialização que sepromove na escola. (p. 139).

Parece óbvio que, com isso, não haveria mesmo necessidade de placas inibidoras da presença da criança negra na escola uma vez que as próprias práticas pedagógicas sinalizam a não pertença dela àquele espaço.

Alguns dados levantados por Souza (2000) são significativos e merecem ser destacados:o baixo índice de profissionais da educação que trabalham com a temática do preconceito; o fatode que a maioria, embora afirme que gostaria de ter um projeto institucionalizado de combate ao racismo, não assume a existência da diferença e, portanto, não reconhece a necessidade de posturas políticas e educativas diversas.

Apropriando-se da concepção de barbárie para Adorno, Oliveira (2000) diz que oprocesso discriminatório que a educação e a pedagogia perpetuam na sociedade tem que ser vistocomo tal, salientando que, para aquele, "a educação contra a barbárie é o objetivo primeiro do trabalho educativo, em favor do qual se deveria secundarizar todos os outros" (p. 110). Assim, assegura que "admitir as práticas racistas como barbárie significa reconhecer o seu caráter destrutivo do psiquismo do negro e a condição de marginalidade para a qual empurram negros e mestiços" (Oliveira, 2000, pp. 110-111).

A autora destaca que a discriminação e o preconceito racial, por estarem nas práticas cotidianas, são formas de violência não física e indica que a pedagogia deveria promover a desestabilização do racismo como barbárie, por meio da desnaturalização da inferioridade racial.Segundo 
ela, isso só seria possível através do conhecimento da História da África, fora da visão eurocêntrica e inferiorizante sob a qual tem sido feita.

Existe a representação de inferioridade negra ligada à pessoa preguiçosa, mau-caráter e pouco inteligente. É perceptível a violência e a barbárie da discriminação e do preconceito racialem nossa sociedade. Tal representação, construída durante toda uma trajetória educacional e de formação docente, precisa ser modificada e isso só se dará através do desenvolvimento da consciência crítica, cujo primeiro momento "é o conhecimento da consciência do outro, é o domínio de como o outro está pensando" (Ianni, 1995 como citado em Oliveira, 2000, p. 116).

Desta forma, a discussão proposta pela autora nos conduz à necessidade de se repensar a formação inicial e continuada de professores(as). Para vencer o problema racial, é preciso que sejam "revistos os currículos da formação desses profissionais [...] que contemple esse problema,o que seguramente contribuirá para tornar sua atividade profissional emancipadora dos destinatários do seu trabalho" (Oliveira, 2000, p. 119).

Isso nos leva a pensar na necessidade de uma formação que sustente o entendimento de educação como valor de refúgio, que favorecerá a formação de aluno-cidadão conhecedor de sua cultura e, consequentemente, o aumento de autoestima e a possibilidade de questionar as desigualdades sociais vigentes.

Outro aspecto que demonstra a relevância das constatações sobre as relações étnico-raciais está ligado ao combate de estereótipos contra o(a) negro(a) cristalizados no senso comum.Devemos levar em conta que as relações étnico-raciais, por serem construídas no cotidiano, fazemparte do 
senso comum e são representadas constantemente. Representações sociais são denominadas por Almeida (2005, p. 122) como

uma forma de conhecimento corrente, dito do senso comum, caracterizado pelas seguintes propriedades: socialmente elaborado e compartilhado, tem uma orientação prática de organização, de domínio do meio (material, social, ideal) e de orientação das condutas e da comunicação; participa do estabelecimento de uma visão de realidade comum a um dado conjunto social (grupo, classe, etc.) ou cultural.

Portanto, estudar as relações étnico-raciais no campo das representações sociais abre a possibilidade de conhecer mecanismos da discriminação e do preconceito na sua forma mais camuflada, pois elas tratam do conhecimento do senso comum, que não é uma simples descriçãoou cópia do estado das coisas, mas sim produzido através da interação e da comunicação, "o conhecimento emerge do mundo onde as pessoas se encontram e interagem, do mundo onde os interesses humanos, necessidades e desejos encontram expressão, satisfação ou frustração" (Moscovici, 2004, p. 9).

A valorização da cultura europeia fez com que as outras etnias, como a indígena e a africana, ficassem relegadas à inferioridade e, em certos casos, à exclusão total. Promover a aculturação de um povo é como tirar sua representação e deixá-lo sem alma, o que certamente repercutirá com gravidade na sua autoestima e valorização como raça. A ideologia da superioridade do branco conserva, em nosso país, elementos no plano estrutural e pessoal que reforçam mecanismos de exclusão e preconceito racial. Tal aspecto assume uma materialidade explícita no campo da educação escolar por meio do vínculo entre conhecimento, identidade e poder. 
Em termos muito amplos, ainda é difícil avaliar a extensão dos efeitos ligados às questõesde raça e etnia no interior da escola, embora tal temática seja pródiga nas abordagens do currículoescolar. Silva (2011) relata que os currículos, as lições, as orientações curriculares oficiais, os rituais escolares, as datas festivas e nacionais, étnicas e raciais são

narrativas que celebram os mitos da origem nacional, confirmam o privilégio das identidades dominantes e tratam as identidades dominadas como exóticas ou folclóricas. Em termos de representação racial, o texto curricular conserva, de forma evidente as marcas da herança colonial. O currículo é, sem dúvida, entre outras coisas, um texto racial. (p. 102).

No campo curricular, a imagem da África e do negro foi moldada pela instituição do escravismo no Brasil pelo colonialismo português. Os negros foram transformados em mercadorias e bens, portanto houve uma dominação sexual, religiosa e linguística. A dominaçãodo colonizador fez com que a autoimagem do(a) brasileiro(a) fosse impregnado por uma ideologiareconciliatória, que, sob o disfarce de uma pretensa "harmonia racial" - afirmada pelo mito da democracia racial entre brasileiros(as) de todas as raças- estava mais propícia a promover a branquitude 3 .

A miscigenação -que se tornou fundamento lógico em um sistema de ideias condutoras ao embranquecimento e ao mito da democracia racial-, a conversão ao catolicismo e a imposiçãodo idioma português para os(as) escravos(as) de diversas procedências foram estratégias de

\footnotetext{
${ }^{3}$ Branquitude se define como uma consciência silenciada quase incapaz de admitir sua participação provocante em conflitos raciais que resiste em aceitar a relacionar-se com a experiência dos que recebema violação do preconceito (Cavalleiro, 2001, p. 72).

216 | INTEREDU № 4 VOL. I (JULIO 2021) PÁGS. 197-227. ISSN: 2735-6523
} 
colonização marcantes para a perda da cultura africana original e a imposição da cultura europeiacolonizadora.

Essa reflexão esclarece como as diferenças têm influenciado socialmente a validação de discursos de hierarquização e inferiorização, consequentemente transformado em desigualdade. A conversão de diferença em desigualdade justifica o discurso legitimador da construção da sociedade injusta. Fatores como o mito da democracia racial e a ideologia do branqueamento têmpermeado esta conversão: "o discurso de branquidade expressa o ressentimento e a confusão de muitos brancos que se sentem vitimizados e amargurados, enquanto mascara desigualdades profundas e práticas de exclusão dentro da ordem social atual" (Giroux \& Simon, 1999, p. 99).

Para os autores, o "discurso da supremacia branca" é um legado histórico da escravização e dasegregação que sustenta uma sociedade racialmente injusta e influencia a pedagogia, como bem comprova o trecho adiante:

Pedagogicamente, isso implica fornecer condições a estudantes para tratar não apenas o modo como sua branquidade funciona na sociedade como marcador de privilégio e poder, mas também como pode ser usada como uma condição para expandir as realidades ideológicas e materiais da vida públicademocrática. Além disso, é imperativo que todos os estudantes compreendam de que modo a raça funciona sistematicamente ao modelar várias formas de representações, relações sociais e estruturas institucionais. Em lugar de propor a erradicação do conceito de raça em si mesmo, professores(as) e outros profissionais da cultura necessitam estruturar práticas pedagógicas que promovam uma reviravolta na questão de raça a fim de indicar de que maneira a branquidade poderia ser renegociada como uma força produtiva dentro de uma 
política de apoio às diferenças ligadas a um projeto democrático racial (Giroux y Simon, 1999, p. 110).

De acordo com os autores, a branquidade constitui um espaço de relação de poder que deve ser questionada e criticada. O início do diálogo seria por meio do conhecimento prévio do aluno decorrente das relações raciais que ele vive em lugares públicos da comunidade. Através do sugerido "espaço para diálogo e crítica", Giroux e Simon (1999) colocam em questionamento a formação identitária de estudantes brancos e negros, pois somente o ensino envolvido com atividades nas quais os estudantes brancos tenham a possibilidade de "examinar suas práticas sociais e sistemasde crenças" (p. 127) de forma crítica, poderá provocar mudanças significativas. Da mesma forma, torna- se imperativo que professores(as) “abordem as histórias que têm modelado o espaço normativo, as práticas e os relacionamentos diversificados que os estudantes brancos herdaram por meio de privilégios raciais" (p. 127). Apenas o estudo deste legado histórico da branquidade poderá despertar neles o "senso de indignação contra a opressão histórica, bem como um desejo de justiça social no presente", acrescentam Giroux e Simon (1999, p. 127).

Essas evidências mostram que as diferenças colocadas por processos naturais são historicamente transformadas em desigualdades e resguardadas por um discurso legitimador quetem justificado relações sociais e educacionais de inferioridade negra. O mito da democracia racial

visa camuflar o racismo e bloquear a organização negra, uma vez que internaliza nos membros da sociedade o engodo da igualdade de oportunidades, reforça o sentimento de inferioridade do negro por não ter "capacidade" de aproveitar tais oportunidades, 
transferindo mais uma vez paraa vítima a culpa da sua situação de miséria e marginalização. (Silva, 1995, p. 34).

Já a ideologia do branqueamento vê, na miscigenação, a possibilidade de aniquilar características fenotípicas negras e forçar a ideia de cultura subalterna. Assim, rever a postura daformação e a prática educativa visa rever esses estereótipos e preconceitos cristalizados.

Vários pesquisadores(as) têm empreendido esforços na busca de soluções para a cristalização da diferença como desigualdade na sociedade brasileira. Dentre eles(as), Gomes (2001, p. 87) alerta para o fim de "macroabordagens da relação escola/sociedade" e da mesma forma "enfatiza quanto à inclusão de novas temáticas", pois a escola é o local onde há o encontrode sujeitos socioculturais e, consequentemente, um local onde a diversidade étnico-cultural se manifesta nas relações.

Gomes (2001) destaca que o papel da cultura é central nesse processo e, dessa forma, não pode ser negligenciada a importância de "novas abordagens educacionais que contemplem o processo de luta e resistência do povo negro" (p. 87). O mero reconhecimento da diversidade étnico-cultural não é suficiente para a transformação das práticas pedagógicas. Contudo, existe "resistência quanto à inclusão de temáticas como cultura, raça/etnia e relações de gênero nas abordagens educacionais" (Gomes, 2001, p. 88). O primeiro passo, segundo a autora, seria um processo de construção da identidade de raça que, por causa da conturbada formação do país, os negros tiveram de forma fragmentada e contraditória.

O processo de branqueamento e o mito da democracia racial marcaram a formação identitária, provocando a aculturação, imposta pelo racismo, e a negação identitária. A pesquisadora apresenta, então, formas alternativas para a superação do racismo e para possibilitarque a 
escola considere diferentes referências de identidade dos negros, também apontando caminhos já percorridos:

Urge que os cursos de formação de professores reelaborem as suas propostas curriculares e incluam a questão racial como um tema a ser estudado e discutido; inclusão de demandas históricas do movimento negro como revisão historiográfica, a inclusão da disciplina História da África nos currículos; elaboração de material didático que combata o racismo, a discriminação raciale de gênero; revisão dos livros que apresentam imagens e textos reforçando a visão estereotipada sobre o negro e a inclusão da questão racial nos currículos escolares; produção teórica educacional que discuta a relação escola/cultura/sociedade, não podendo desconsiderar que a questão racialassume um lugar de destaque na formação da nossa sociedade (Gomes, 2001, p. 89).

O fragmento alerta para a necessidade de atentarmos para o papel central da cultura e do seu processo histórico de construção. Nesse sentido, o estudo de Oliveira (2009) sobre o legado de Munanga para uma fundamentação filosófica de uma postura antirracista de educação confirmaque essa postura tem papel fundamental não apenas como local de socialização, mas, acima de tudo, como "promotora da alteridade" nas relações sociais. Seria uma postura diferenciada daquela de apenas "formar pessoas, de acordo com padrões sociais e então enquadrá-los nesses padrões pré-concebidos, como se isso representasse um modelo de socialização"; tampouco se trata de uma educação visionária, afastada da realidade, apartada "da responsabilidade para com a vida e criando um mundo de fantasia" (Oliveira, 2009, p. 2). Assim, a autora, assegura que: 
As ideias pedagógicas estudadas no Brasil têm suas raízes na filosofia ocidental. Nessa perspectiva, outros valores civilizatórios, como os africanos, são excluídos da pedagogia, assim como da Filosofia, da Psicologia, da Física, da Biologia etc. As culturas africanas são consideradas apenas como do campoda Etnografia e, em alguns casos, da Sociologia e da História. Há um desconhecimento sobre a forma de pensar, sobre a visão de mundo, sobre umaeducação fundada na cultura mítico-filosófica africana. Os pensadores africanos e afrodescendentes como Amadou Hampâté Bã, Kwame Anthony Appiah, Wande Abimbola, Léopold Sedar Senghor, Paulin Hountondji, Kwasi Wiredu, Aimé Césaire, William Edward Burghardt DuBois, Marcien Towa, Ben Oguah, Barry Hallen, Ivan Karp, Boubou Hama, Oumar Ba, Joseph KiZerbo, Jan Vansina, Cheik Anta Diop, Adu Boahen, Kabengele Munanga, Petronilha Beatriz Gonçalves e Silva, Deoscóredes Maximiliano dos Santos (mestre Didi), entre tantos outros, são desconhecidos em nossos cursos (Oliveira, 2009, p. 3).

Para a pesquisadora, a proposta de Munanga esclarece o papel mediador da escola, cuja função é integrar o indivíduo nos aspectos intelectuais e objetivos, facilitando-lhe uma visão e umentendimento de si como parte de e como a própria totalidade, numa relação de absoluta corresponsabilidade, em que o que tem maior importância não é nem o eu nem o outro e sim o " $\mathrm{e}$ " capaz de congregar sem desfigurar ou aniquilar a diferença, que é o verdadeiro sentido da relação, pois se não houvesse a diferença tudo acabaria relacionando-se com o mesmo.

As características da sociedade brasileira evidenciam, pelos índices, que, na prática social, o racismo e preconceito racial marcam profunda e cotidianamente o povo, e que a escola,como uma instituição social, não é isenta, já que, nos seus rituais pedagógicos, muitas vezes, também repete práticas racistas e preconceituosas. Nesse sentido, é preciso que os(as) 
professores(as), em sua formação, tenham oportunidade de subsidiar o combate ao racismo e à discriminação. Conforme apregoa Silva (2001, p. 168), “as práticas racistas constroem-se e são reiteradamente repetidas a partir de preconceitos, frutos da ignorância que grupos étnicos tidos como superiores têm acerca da história das organizações e modo de vida daqueles consideradosinferiores".

Os movimentos negros buscam se organizar para discutir a questão e articular formas de intervenção. Assim, embora o desconhecimento tanto na sociedade quanto na história da educação brasileira - de propostas pedagógicas desenvolvidas pelo movimento negro apresente- se como um problema a ser superado, em diversos estados brasileiros surgem propostas de ações pedagógicas. Conforme Lima (2009, p. 36), os movimentos negros brasileiros foram "para além da denúncia do racismo e das desigualdades raciais perpetuadas historicamente nos sistemas de ensino", eles elaboraram "propostas pedagógicas e de intervenção em contraposição a um cotidiano singular e etnocêntrico nos espaços educacionais".

\section{CONSIDERAÇÕES FINAIS}

É perceptível que o espaço escolar ainda apresenta dificuldades para lidar com a diversidade de situações que movimenta esse local, em especial quando dizem respeito às questões raciais. Na maioria das vezes, o que ocorre é que a escola se acomoda em viver dentro de um imenso caixote e, ali, os olhares projetados para o outro, para o diferente ou para aquilo que é estranho a sua rotina são neutralizados pela tentativa de padronização de uma realidade plural, mas tratada no singular. Com isso, não consegue desfazer-se de pré-conceitos e de valorespré-concebidos, 222 | INTEREDU № 4 VOL. I (JuLIO 2021) PÁGs. 197-227. ISSN: 2735-6523 
nem ensinar a respeitar e a se colocar no lugar do outro, a fim de que se possa compreender as atitudes, os valores pregados e a postura assumida.

O que a escola deve valorizar é a pluralidade etnicorracial que constitui humana e culturalmente esse espaço, incentivando e recuperando as pertenças que cada aluno tem com suaetnia e formação sociocultural, mostrando que na diversidade está presente o respeito mútuo. Assim todos têm direitos de ter suas práticas culturais e suas percepções de mundo compreendidase respeitadas no espaço da escola e da sala de aula.

É necessário que o educador seja realmente um mediador de aprendizagens significativas e torne efetivo e pleno o processo de transformação escolar. Para isso, é necessário que ele atue contra a exclusão e a favor da promoção da igualdade racial, discutindo o espaço da escola, suasaulas, o respeito ao outro e o sentir-se no outro do outro ou exercitar isso se colocando no lugar do outro, da realidade desse outro, percebendo se os conhecimentos estudados estão contribuindopara a ressignificação de posturas e atitudes.

Portanto, o processo de implementação da Lei $\mathrm{n}^{\mathrm{o}} 10.639$ (2003) e sua aplicação consciente depende da sensibilidade do(da) docente em valorizar, inovar, ser criativo(a), crítico(a) e auto reflexivo(a) no que tange às escolhas didáticas e pedagógicas a serem efetivadas no espaço escolar e na sala de aula, deixando claro para seus(suas) alunos(as) a importância de se trabalhar e valorizar a cultura africana e afro-brasileira no espaço escolar como possibilidade de compreensão da alteridade e do respeito ao outro.

Na perspectiva pós-pandêmica esses pressupostos fazem-se ainda mais emergentes porque as diferenças de acesso e permanência na escola foram muito mais destacados. Uma grande parte da população negra não possui acesso às tecnologias, não conseguiram acesso à internet, ficaram desempregados/as, enfim, aumentaram ainda mais a vulnerabilidade com 
relaçãoaos processos educacionais. O que o contexto histórico de exclusão educacional pode nos ensinar? $\mathrm{O}$ que o momento pandêmico pode revisitar nesse contexto histórico para que possa modificar asdificuldades educacionais da população negra?.

Entendemos que essa conversa permanecerá aberta e sem uma definição final. Contudo, que a história possa nos ensinar como evitar mais processos educativos racistas e que, na contramão disso, possa viabilizar políticas públicas corretivas e inclusivas. Assim, entendemos que o Brasil possa ser um país mais democrático e antirracista, o que só poderá contribuir para oseu crescimento.

\section{REFERÊNCIAS BIBLIOGRÁFICAS}

Almeida, Â. M. de O. (2005). A pesquisa em representações sociais: proposições teórico- metodológicas. In Santos, M. de F., \& Almeida, L. M. (Orgs.) Diálogos com a teoria darepresentação social. Recife: Editora Universitária da UFPE.

Brasil. Constituição da República Federativa do Brasil de 1988. (1988). Brasília, DF:Senado Federal.

Brasil. Parâmetros Curriculares Nacionais. (1997). Recuperado em 29 out. 2020, de http://portal.mec.gov.br/seb/arquivos/pdf/livro101.pdf.

Candau, V. M. F. (2002, agosto). Sociedade, cotidiano escolar e cultura(s): uma aproximação. Educação e Sociedade, 23(79), 125-162. Recuperado em 18 nov. 2020, de https://www.scielo.br/pdf/es/v23n79/10852.pdf.

Canen, A. (1997). A formação de professores: diálogos das diferenças. Ensaio: avaliação e políticas públicas em Educação, 5(17), 477-494.

Cavalleiro, E. (org.). (2001). Racismo e anti-racismo na educação: repensando nossas escolas. SãoPaulo: Summus. 
Giroux, H. A.; Simon, R. (1999). Popular culture and a critical pedagogy: everyday life as a basis forcurriculum knowledge. In Mclaren, P., \& Giroux, H. (Orgs.). Critical pedagogy, the state, and a cultural struggle. Albany: State University of New York Press.

Gomes, N. L. (2001). Educação cidadã, etnia e raça: o trato pedagógico da diversidade. In Cavalleiro, E. (Org.). Racismo e anti-racismo na educação: repensando nossas escolas. SãoPaulo: Summus. pp. 83-96.

Gontijo, R. (2003). Identidade nacional e ensino de história: a diversidade como "patrimônio sociocultural". In Abreu, M., \& Soihet, R. (Orgs.). Ensino de história: conceitos, temáticas e metodologia. Rio de Janeiro: Casa da Palavra. pp. 55-79.

Jodelet, D. Os processos psicossociais da exclusão. (1999). In Sawaia, B. (org.). As artimanhas da exclusão. Petrópolis, SP: Vozes. pp. 53-66.

Lei no 9.394, de 20 de dezembro de 1996. Lei de Diretrizes e Bases da Educação Nacional. (1996). Estabelece as diretrizes e bases da educação nacional. Brasília, DF.

Lei no 10.639, de 9 de janeiro de 2003 (2003). Altera a Lei no 9.394, de 20 de dezembro de 1996, que estabelece as diretrizes e bases da educação nacional, para incluir no currículo oficial da Rede de Ensino a obrigatoriedade da temática "História e Cultura Afro-Brasileira", e dá outras providências. Diário Oficial da União. Brasília, DF.

Lima, I. C. (2009). As propostas pedagógicas do movimento negro no Brasil. Dissertação de Mestrado, Universidade Federal do Ceará. Fortaleza, CE, Brasil.

Moscovici, S. (2004). Representações sociais: investigações em psicologia social. ( $3^{\text {a }}$ ed). Petrópolis, RJ: Vozes.

Munanga, K. (1999). Rediscutindo a mestiçagem no Brasil: identidade nacional versus identidadenegra. Petrópolis, RJ: Vozes. 
Cairo Mohamad Ibrahim Katrib y Luciane Ribeiro Dias Gonçalves

Oliveira, E. de. (2000). Relações raciais e educação: recolocando o problema. In Lima, I. C., \& Silveira, S. M. Negros, territórios e educação. (Série Pensamento negro em educação). Florianópolis: Atilénde. pp. 105-122.

Oliveira, F. (2004). Ser negro no Brasil: alcances e limites. Estudos Avançados, 18(50), 57-60. Recuperado em 15 jan. 2021, de https://www.scielo.br/scielo.php?script=sci_arttext\&pid=S010340142004000100006. DOI: 10.1590/S0103-40142004000100006.

Oliveira, J. M. de. (2009). Africanidades e educação: ancestralidade, identidade e oralidade no pensamento de Kabengele Munanga. Tese de Doutorado, Universidade de São Paulo. São Paulo, SP, Brasil.

Oliveira, R. G.; Cunha, A. P. da; Gadelha, A. G. S.; Carpio, C. G.; Oliveira, R. B., \& Corrêa, R. M. (2020, setembro). Desigualdades raciais e a morte como horizonte: considerações sobre a COVID-19 e o racismo estrutural. Cad. Saúde Pública, 36(9), 1-14. Recuperado em 10 jan. 2021, de https://www.scielo.br/scielo.php?script=sci_arttext\&pid=S0102311X2020000903003. DOI: 10.1590/0102-311x00150120

Pinto, R. P. (2000). A escola como espaço de reflexão: atuação no campo das relações étnico-raciais. In Lima, I. C., \& Silveira, S. M. (Orgs.). Negros, territórios e educação. (Série Pensamento negro em educação). Florianópolis: Atilénde. pp. 126-136.

Silva, A. C. (1995). A discriminação do negro no livro didático. Salvador: CEAO; CED.

Silva, P. B. G. (2000). Dimensões e sobrevivências de pensamentos em educação em territórios africanos e afro-brasileiros. In Lima, I. C., \& 
Silveira, S. M. Negros, territórios e educação. (Série Pensamento negro em educação). Florianópolis: Atilénde. pp. 70-78.

Silva, T. T. da. (2011). Documentos de identidade: uma introdução às teorias do currículo. Belo Horizonte: Autêntica.

Silvério, V. (2005). Afirmando diferenças: montando o quebra-cabeça da diversidade na escola. Campinas, SP: Papirus.

Souza, I. S. (2000). Os educadores e as relações interétnicas na escola. In Lima, I. C., \& Silveira, S. M. Negros, territórios e educação. (Série Pensamento negro em educação). Florianópolis: Atilénde, p. 137151.

Souza, R. M. de, \& Gallo, S. (2002, agosto). Por que matamos o barbeiro? Reflexões preliminares sobre a paradoxal exclusão do outro. Educação E Sociedade, 23(79), 39-73. Recuperado em 5 nov. 2020, de https://www.scielo.br/pdf/es/v23n79/10848.pdf. 